\title{
Glucocorticoid Induction of Epinephrine Synthesizing Enzyme in Rat Skeletal Muscle and Insulin Resistance
}

Brian Kennedy, Hamzeh Elayan, and Michael G. Ziegler

Division of Nephrology, Department of Medicine, University of California, San Diego Medical Center, San Diego, California 92103

\begin{abstract}
Rat skeletal muscle contains two enzymes which can make epinephrine: phenylethanolamine $\boldsymbol{N}$-methyltransferase (PNMT) and nonspecific $\boldsymbol{N}$-methyltransferase. We studied the timecourse and mechanism by which the glucocorticoid dexamethasone increases muscle PNMT activity. We also examined the hypothesis that increased muscle $\mathbf{E}$ synthesis may contribute to glucocorticoid-induced insulin resistance. Dexamethasone (1 $\mathrm{mg} / \mathrm{kg}$ s.c. for $12 \mathrm{~d}$ ) increased muscle PNMT activity sevenfold but did not change NMT activity. Immunotitration with an anti-PNMT antibody indicated that the PNMT elevation was due to increased numbers of PNMT molecules. Dexamethasone rapidly increased PNMT activity and this elevation was largely maintained $6 \mathrm{~d}$ after glucocorticoid treatment stopped. Muscle epinephrine levels were transiently elevated by dexamethasone. Dexamethasone-treated rats had elevated insulin levels after a glucose load, and chronic administration of the PNMT inhibitor SKF 64139 reversed this increase. Chronic SKF 64139 improved glucose tolerance in normal rats.

Dexamethasone induced muscle synthesis of the epinephrine-forming enzyme PNMT. A PNMT inhibitor lowered insulin levels in glucocorticoid-treated rats and glucose levels in untreated rats. These findings are compatible with antagonism of insulin-mediated glucose uptake by epinephrine synthesized in skeletal muscle. (J. Clin. Invest. 1993. 92:303-307.) Key words: phenylethanolamine $N$-methyltransferase $\bullet$ epinephrine - insulin resistance $\bullet$ muscle
\end{abstract}

\section{Introduction}

Epinephrine $(E)^{1}$ is synthesized by methylation of NE (1). At least two different enzymes are capable of catalyzing this $N$-methylation: phenylethanolamine $N$-methyltransferase (PNMT) and nonspecific $N$-methyltransferase (NMT) $(1,2)$. In rats PNMT activity is greatest in the adrenal gland, but it is also present in several brain areas, heart, lung, and skeletal muscle $(1,3)$. In humans, PNMT activity has been documented in adrenal (4), brain (5), uterus (6), and red blood

Address correspondence to Dr. Brian Kennedy, Division of Nephrology, Department of Medicine, UCSD Medical Center, 225 Dickinson Street, San Diego, CA 92103-8341.

Received for publication 24 September 1992 and in revised form 11 February 1993.

1. Abbreviations used in this paper: DA, dopamine; E, epinephrine; NMT, nonspecific $N$-methyltransferase; PNMT, phenylethanolamine $N$-methyltransferase; SAM, $S$-adenosylmethionine.

J. Clin. Invest.

(c) The American Society for Clinical Investigation, Inc.

0021-9738/93/07/0303/05 \$2.00

Volume 92, July 1993, 303-307 cells $(6)$. We $(7-10)$ and others $(11,12)$ have provided evidence that many extra-adrenal tissues in rats can synthesize $\mathrm{E}$ in vivo using PNMT and/or NMT.

Glucocorticoids increase PNMT levels in the rat adrenal $(13,14)$, heart (10), and lung (9) tissues, and $E$ levels in some of these tissues are also increased $(10,13)$. We recently found that rat muscle PNMT is increased fivefold following chronic dexamethasone treatment (10). If muscle $\mathrm{E}$ synthesis is also elevated, muscle physiology could be profoundly affected. Stimulation of muscle $\beta$ receptors by $\mathrm{E}$ causes increased potassium uptake (15), increased contractility (16), and decreased insulin-mediated muscle glucose uptake (17-19). Like E, glucocorticoids reduce insulin-mediated muscle glucose uptake $(18,20$, 21 ) and cause insulin resistance in animals and humans (2224). This similarity raises the possibility that enhanced muscle E synthesis may contribute to the insulin resistance induced by dexamethasone treatment.

We examined several characteristics of muscle $\mathrm{E}$ forming enzymes including their response to glucocorticoid treatment, substrate specificity, and inhibition by an anti-PNMT antibody or PNMT inhibitor. We also performed an experiment that begins to test the hypothesis that glucocorticoid-induced insulin resistance is mediated by augmented muscle E synthesis.

\section{Methods}

Effect of chronic dexamethasone, adrenal demedullation, and adrenalectomy. Chronic administration of dexamethasone to adrenalectomized rats greatly elevates muscle PNMT. The first experiment was performed to determine if chronic dexamethasone treatment can also increase muscle PNMT when the adrenal cortex is present and functional. Male Sprague-Dawley rats (Harlan Sprague Dawley, Inc., Indianapolis, IN) weighing from 250 to $270 \mathrm{~g}$ were allocated into four groups: a sham-operated group, an adrenal-demedullated group, a dexamethasone-treated adrenal-demedullated group, and an adrenalectomized group. The adrenalectomized group was included in this experiment to determine the effect of removing the source of most endogenous glucocorticoids.

We surgically removed the adrenal medullae of 12 rats under pentobarbital anesthesia. Both adrenal glands (cortex plus medulla) were removed from six additional rats. These six adrenalectomized rats were provided saline in the place of water. An additional eight rats were sham-operated. $3 \mathrm{~d}$ after surgery, half of the adrenal-demedullated rats were given the first of 12 daily injections of dexamethasone $(1 \mathrm{mg} / \mathrm{kg}$ s.c.). The remaining rats received vehicle alone. The rats were decapitated and a 300 -mg segment of masseter muscle was collected, weighed, and frozen at $-70^{\circ} \mathrm{C}$. Trunk blood was collected for determination of plasma E levels by radioenzymatic assay (25). Homogenates of the muscle samples were later prepared and assayed for PNMT and NMT activity using the method of Ziegler et al. (26). Briefly, samples were incubated for $2 \mathrm{~h}$ at $25^{\circ} \mathrm{C}$ with $1 \mathrm{mM} \mathrm{NE}$ or DA and $1.37 \mu \mathrm{M}^{3} \mathrm{H}-S$ adenosylmethionine $\left({ }^{3} \mathrm{H}-\mathrm{SAM}\right)$ in tris- $\mathrm{HCl}$ buffer, $\mathrm{pH}$ 8.6. After incubation, samples were shaken with alumina for $5 \mathrm{~min}$. The samples were then washed with ice-cold water and the catecholamines were eluted from the alumina with $0.1 \mathrm{M} \mathrm{HClO}_{4}$. Excess ${ }^{3} \mathrm{H}-\mathrm{SAM}$ was then precipi- 
tated, the supernate was transferred to vials, scintillant was added, and the radioactivity quantified on a liquid scintillation counter. The tissue concentrations used in these studies were within the range for which enzyme activity is proportional to tissue concentration.

Immunotitration. Immunotitration experiments were performed to determine if the increases in muscle $\mathrm{N}$-methylating activity following chronic dexamethasone were due to activation of PNMT enzymatic activity or induction of more PNMT. Immunotitration was performed using a modification of the procedure of Wong et al. (27). Six $50-\mu \mathrm{l}$ aliquots of muscle homogenates from each of three dexamethasone-treated $(1 \mathrm{mg} / \mathrm{kg}$ per d s.c., $12 \mathrm{~d})$ and each of three vehicle treated rats were prepared. Aliquots of these homogenates had been previously assayed for $\mathrm{N}$-methylating activity and the homogenates from dexamethasone-treated rats were diluted about fivefold with buffer to reduce their PNMT activity to levels found in the control homogenates.

$50 \mu \mathrm{l}$ of buffer containing $0.03125,0.0156,0.0078,0.0039$, or 0.00195 or $0 \mu \mathrm{l}$ of anti-bovine adrenal PNMT antiserum were added to the six muscle aliquots from each rat. Samples were vortexed and incubated for $1 \mathrm{~h}$ at $37^{\circ} \mathrm{C}$ then for $16 \mathrm{~h}$ in an ice bath. Samples were then centrifuged at $11,000 \mathrm{~g}$ for $6 \mathrm{~min}$ at $4^{\circ} \mathrm{C}$. Aliquots of the supernates were then assayed for PNMT activity in the usual manner. If dexamethasone increases $\mathrm{N}$-methylating activity by elevating the number of enzyme molecules, then when dexamethasone homogenates are diluted to control activity levels the dexamethasone homogenates should be inhibited by anti-PNMT antibody to the same extent as control homogenates.

The antiserum was a generous gift from Dr. Dona Lee Wong and was generated in male New Zealand white rabbits against $S$-adenosylhomocysteine-AH-Sepharose 4B purified bovine PNMT. One $\mu$ l of antiserum failed to inhibit $\mathrm{N}$-methylating activity from atria, ventricle, or skeletal muscle homogenates when DA was used as substrate. In contrast, very low antiserum concentrations inhibited PNMT in these tissues when NE was used as substrate.

Rate and duration of PNMT induction by dexamethasone. In this experiment we determined how rapidly muscle PNMT activity is increased by dexamethasone and how long this elevation persists once dexamethasone treatment is terminated. 36 male Sprague-Dawley rats were adrenalectomized and $3 \mathrm{~d}$ later were allocated into seven groups. Six of the groups were injected with dexamethasone at $0.5 \mathrm{mg} / \mathrm{kg}$ b.i.d. subcutaneously and one group was injected with vehicle alone. One of the six dexamethasone-treated groups was injected for $3 \mathrm{~d}$, another for $5 \mathrm{~d}$, and the remaining four groups for $7 \mathrm{~d}$. One of the groups that was treated with dexamethasone for $7 \mathrm{~d}$ was decapitated shortly after the final dexamethasone injection. The three other 7-d dexamethasone groups were given the glucocorticoid receptor antagonist RU 486 (5 $\mathrm{mg} / \mathrm{kg}$ p.o.; gift of Dr. Samuel Yen) $12 \mathrm{~h}$ after the final dexamethasone injection to abruptly end the action of dexamethasone. These rats were decapitated either 1,3 , or $6 \mathrm{~d}$ later. Trunk blood was collected from all rats after decapitation, and was assayed for $E$ levels to determine the efficacy of adrenalectomy. A 300-mg segment of masseter muscle was collected from each rat, weighed, and frozen. The muscle was assayed for E levels by the radioenzymatic method of Kennedy and Ziegler (25) and PNMT activity was also determined.

Effect of in vivo PNMT inhibition on dexamethasone-induced insulin resistance. To examine the hypothesis that muscle $E$ synthesis contributes to the insulin resistance induced by dexamethasone, we adrenalectomized 13 rats and sham-operated 10 others. We then injected all of the adrenalectomized rats and five of the sham-operated rats with dexamethasone at $1 \mathrm{mg} / \mathrm{kg}$ per $\mathrm{d}$ for $12 \mathrm{~d}$ and injected the remaining rats with vehicle alone. Similar or lower doses of dexamethasone have repeatedly been shown to induce hyperinsulinemia or insulin resistance, or both, in rats $(21,28-31)$. The fifth day after starting the dexamethasone injections we gave six of the adrenalectomized rats the PNMT inhibitor SKF 64139 at $50 \mathrm{mg} / \mathrm{kg}$ b.i.d. for $6 \mathrm{~d}$. The other rats received injections of vehicle. On the tenth day after starting the dexamethasone injections all rats were deprived of food for $24 \mathrm{~h}$ and an intraperitoneal glucose tolerance test was performed according to a previously described method (32) with the exception that rats were anesthetized with ether during blood drawing. Briefly, the test involved collection of about $250 \mu \mathrm{l}$ of tail blood for determination of serum insulin and plasma glucose levels. Immediately after this, each rat was given an intraperitoneal injection of a $20 \%$ glucose solution. 10,30 , and 50 min later additional samples of tail blood were collected. Plasma glucose was determined by the glucose oxidase method using a glucose analyzer (model 23A; Yellow Springs Instrument Co., Yellow Springs, $\mathrm{OH})$. Serum insulin was measured by radioimmunoassay (33). One day after the glucose tolerance test, the rats were decapitated. Trunk blood was collected and the plasma saved for $\mathrm{E}$ assay to verify adrenalectomy. A 300-mg segment of masseter muscle was also collected from each rat for determination of PNMT activity and $E$ levels.

We performed an additional experiment to determine the effects of SKF 64139 on blood insulin and glucose levels in normal rats with intact adrenals. Six rats were treated with the PNMT inhibitor at 50 $\mathrm{mg} / \mathrm{kg}$ b.i.d. for $6 \mathrm{~d}$ and six rats received vehicle alone. On the sixth day of injections, an intraperitoneal glucose tolerance test was performed in these rats by the same method as in the previous experiment. Blood insulin and glucose levels were determined as previously described. A few hours after the end of the glucose tolerance test all rats were decapitated and trunk blood was collected for determination of plasma $\mathrm{E}$ levels.

Statistics. In experiments where three or more groups of subjects were being compared the overall statistical significance of intergroup differences was determined by one-way ANOVA. When the one-way ANOVA was significant, the statistical significance of differences between any two specific groups was assessed by Tukey's test. The overall significance of intergroup differences in glucose and insulin levels during the glucose tolerance test was determined using a two-way ANOVA mixed model. When the two-way ANOVA mixed model was significant, the Newman-Keuls test was used to calculate the significance of differences between any two specific groups.

\section{Results}

The enzyme PNMT methylates NE well and DA poorly whereas NMT readily methylates both of these amines $(1,34)$. Muscle homogenates readily methylated NE to form E and methylated DA to form epinine. It is well established that adrenal PNMT activity is increased by the glucocorticoid dexamethasone $(13,14)$. Dexamethasone treatment also increased PNMT in muscle, but not NMT activity (Fig. 1). E levels in trunk blood from decapitated control rats averaged $6,681 \pm \mathrm{pg} /$ $\mathrm{ml}$. E levels in adrenalectomized and adrenal-demedullated rats were routinely more than 100 -fold lower than this.

Increased muscle $\mathrm{E}$ forming activity could result from either PNMT activation or an increase in the number of PNMT molecules. To address this issue, we diluted muscle homogenates from three dexamethasone-treated rats with buffer so that they had levels of $\mathrm{E}$ forming activity similar to those in three control rats. When increasing concentrations of antiPNMT antibody were added to homogenates from both groups, the extent of inhibition was very similar (Fig. 2).

Muscle PNMT increased linearly over baseline levels during the dexamethasone injection period. Shortly after the last dexamethasone injection, the glucocorticoid antagonist RU 486 was given, to rapidly terminate stimulation of glucocorticoid receptors. Nevertheless, muscle PNMT activity remained at maximal levels for $3 \mathrm{~d}$ before starting to decline after an additional $3 \mathrm{~d}$ (Fig. $3 \mathrm{~A}$ ). E levels in muscle homogenates were higher during dexamethasone administration up to day 5 , then dropped at day 7 and after treatment stopped (Fig. $3 \mathrm{~B}$ ).

Dexamethasone-treated adrenalectomized rats had high serum insulin levels. The PNMT inhibitor SKF 64139 returned insulin levels to those found in control rats that did not 

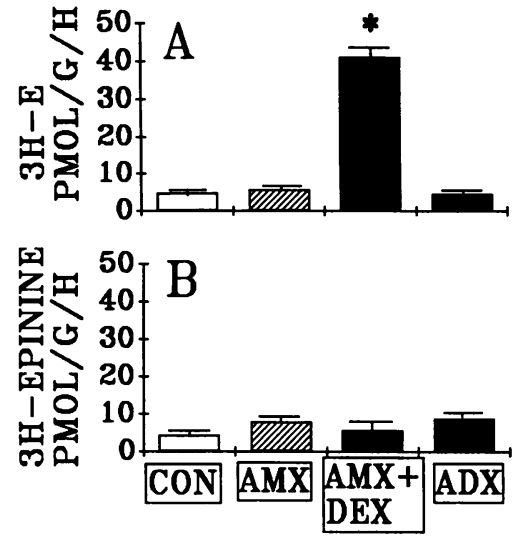

Figure 1. $(A){ }^{3} \mathrm{H}$-epinephrine synthesis and $(B){ }^{3} \mathrm{H}$-epinine synthesis by muscle homogenates from four groups of rats: sham-operated controls (CON), adrenal-demedullated rats (AMX), adrenal-demedullated rats treated chronically with dexamethasone $(1 \mathrm{mg} / \mathrm{kg}$ per $\mathrm{d}$ for $12 \mathrm{~d}$ ) (AMX + DEX), adrenalectomized rats (ADX). Values are expressed in

$\mathrm{pmol} / \mathrm{g}$ wet wt muscle per $\mathrm{h}$ and are means \pm SEM of determinations from the 6-9 rats per group. Intergroup differences are significant by ANOVA $P<0.001^{*} P<0.05$ vs. all other groups by Tukey's test.

receive glucocorticoid (Fig. $4 A$ ). Intergroup differences in insulin were highly significant $(P=0.0002)$ by two-way ANOVA mixed model. Unlike insulin, plasma glucose was elevated to a similar extent in all groups following intraperitoneal glucose injection (Fig. $4 \mathrm{~B}$ ).

Plasma E levels were less than $10 \mathrm{pg} / \mathrm{ml}$ in blood collected from all three groups of adrenalectomized rats $1 \mathrm{~d}$ after the glucose tolerance test. In contrast, plasma $E$ levels in the shamoperated group were $2,513 \pm 544 \mathrm{pg} / \mathrm{ml}$ and they were $2,771 \pm 646 \mathrm{pg} / \mathrm{ml}$ in the dexamethasone-treated sham group. Muscle $\mathrm{E}$ levels differed between groups $(P=0.009$ by ANOVA). The Newman-Keuls test indicated that this was due solely to the much higher muscle $\mathrm{E}$ levels in dexamethasonetreated sham-operated rats $(877 \pm 127 \mathrm{pg} / \mathrm{g})$ than in adrenalectomized dexamethasone-treated rats $(231 \pm 73 \mathrm{pg} / \mathrm{g})$. No other intergroup differences reached statistical significance.

Glucocorticoid treatment increased muscle PNMT activity in both sham-operated rats $(26 \pm 3 \mathrm{pmol} / \mathrm{g}$ per $\mathrm{h})$ and in adrenalectomized rats ( $37 \pm 2 \mathrm{pmol} / \mathrm{g}$ per $\mathrm{h}$ ). SKF 64139 reduced muscle PNMT activity in glucocorticoid-treated rats to levels $(6 \pm 2 \mathrm{pmol} / \mathrm{g}$ per $\mathrm{h})$ near those of untreated rats $(3 \pm 2 \mathrm{pmol} / \mathrm{g}$ per h).

In a separate experiment, chronic treatment of normal rats with SKF 64139 reduced the magnitude of the glucose elevation following an intraperitoneal glucose load (Fig. 5). Even though these rats had intact adrenals, chronic SKF 64139 reduced $(P<0.001)$ E levels in trunk blood collected at decapita-

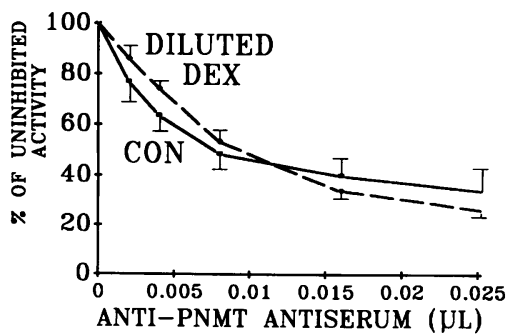

Figure $2 .{ }^{3} \mathrm{H}-\mathrm{E}$ synthesis by muscle homogenates from three rats treated chronically with dexamethasone (DEX) and from three vehicle-injected control rats $(\mathrm{CON})$. Homogenates from dexamethasonetreated rats were diluted approximately fivefold with buffer so they would have similar activity to control homogenates. Homogenates from both types of rats were incubated in the presence of 0 to $0.025 \mu \mathrm{l}$ anti-PNMT antiserum. Results are expressed as percent of $E$ forming activity in the absence of antiserum and are means \pm SEM.

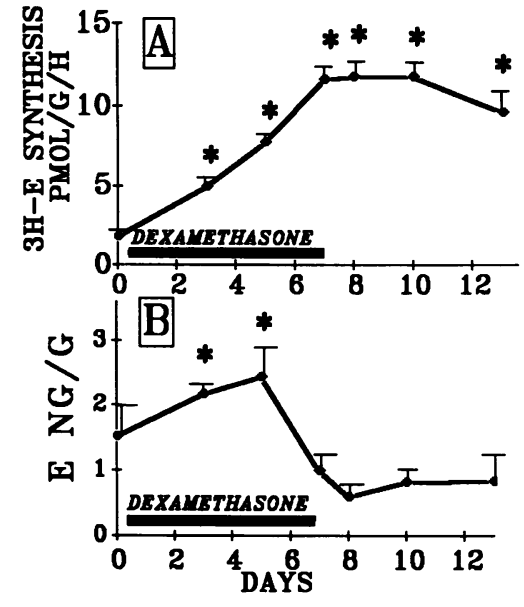

Figure 3. $(A){ }^{3} \mathrm{H}$-epinephrine synthesis by muscle homogenates from adrenalectomized rats treated with dexamethasone for $0,3,5$, or $7 \mathrm{~d}$. Results are expressed in $\mathrm{pmol} / \mathrm{g}$ wet wt muscle per $h$. Values are mean \pm SEM of homogenates from 5-6 rats. Intergroup differences are significant by ANOVA $(P<0.001)$ ${ }^{*} P<0.05$ vs. vehicleinjected controls by Tukey's test. $(B)$ Epinephrine levels in aliquots of the same muscle homogenates described in $(A)$. Results are expressed in $\mathrm{ng} / \mathrm{g}$ wet wt muscle. Intergroup differences are significant by ANOVA $(P<0.001){ }^{*} P<0.05$ vs. days 8 and 10 by Tukey's test.

tion to $1,948 \pm 491 \mathrm{pg} / \mathrm{ml}$, from a level of $5,160 \pm 472 \mathrm{pg} / \mathrm{ml}$ in control rats.

\section{Discussion}

The enzymes PNMT and NMT are found in varying proportions in many tissues ( 3 ). They can be differentiated by their substrate specificity, and the degree to which their enzymatic activity is blocked by PNMT inhibitors and anti-PNMT antibody. Rat skeletal muscle appears to contain mainly PNMT, because most of its $\mathrm{N}$-methylating activity was inhibited by anti-PNMT antibody. Also, muscle methylates DA at about the same rate as NE, whereas tissues containing exclusively NMT methylate DA about three times faster than NE (34).

Adrenal PNMT is induced by glucocorticoids $(13,14)$. We have recently shown that PNMT activity in other tissues is also increased by glucocorticoid treatment $(9,10)$. Here, using immunotitration, we show that glucocorticoid-induced increases

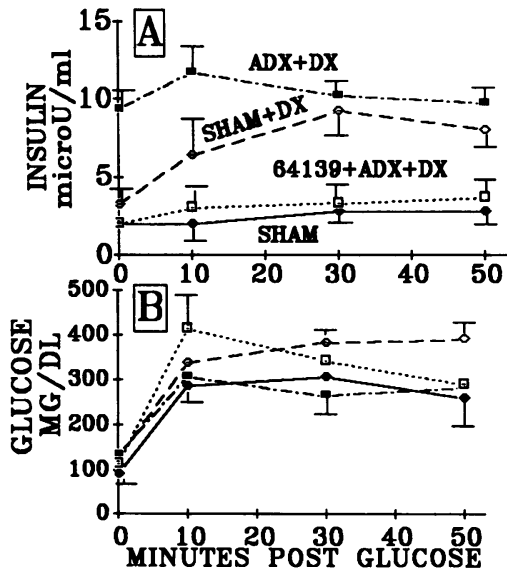

Figure 4. ( $A$ ) Serum insulin and $(B)$ plasma glucose during a glucose tolerance test given to four groups of rats: shamoperated rats (SHAM), dexamethasone-treated sham-operated rats (SHAM + DX), dexamethasone-treated adrenalectomized rats (ADX + DX), and adrenalectomized dexamethasonetreated rats given the PNMT inhibitor SKF 64139 (64139 + ADX + DX). Symbols for each group are the same in both graphs. Values are means \pm SEM of determinations made from five to seven rats. Overall intergroup differences in insulin were significant by two-way ANOVA mixed model $(P=$ 0.0002 ). On the basis of the Newman-Keuls test insulin levels were higher $(P<0.05)$ in ADX + DX rats than in SHAM + DX rats, which in turn were higher $(P<0.05)$ than both SHAM and $64139+$ $\mathrm{ADX}+\mathrm{DX}$ rats. 


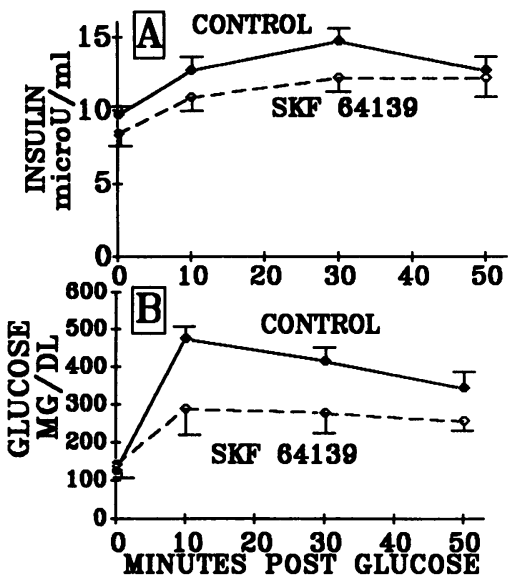

The group by time interaction for plasma glucose values was also significant $(P=0.003)$ by two-way ANOVA mixed model.

in muscle PNMT activity are due to increased numbers of PNMT molecules rather than activation of preexisting PNMT molecules.

The elevation of PNMT activity induced by dexamethasone treatment is rapid and longlasting. PNMT activity doubled by the third day of treatment and was elevated about fivefold by day 7. After dexamethasone treatment was terminated, PNMT activity remained at peak levels for $3 \mathrm{~d}$ and declined from peak values by only $18 \%$ after 3 more $d$.

Muscle $\mathrm{E}$ levels tended to increase after 3 and $5 \mathrm{~d}$ of dexamethasone treatment but dropped rapidly thereafter. Changes in muscle $E$ levels are probably not due to changes in uptake of circulating $\mathrm{E}$, because plasma $\mathrm{E}$ levels in trunk blood collected upon decapitation of these adrenalectomized rats averaged less than $30 \mathrm{pg} / \mathrm{ml}$. Thus, increased muscle E synthesis is likely to account for the transient elevations in muscle $E$ that we observed. The elevation in muscle $\mathrm{E}$ induced by dexamethasone was transient, whereas the PNMT elevation was maintained several days after treatment ended. This discrepancy may be due to increases in the activity of the catecholamine catabolizing enzyme catechol-o-methyl transferase (COMT) in muscle, because dexamethasone elevates this enzyme in a number of tissues, including cardiac ventricle (10). Increased COMT activity could reduce $E$ levels even in the presence of augmented synthesis, because $E$ levels are a function of both its rate of synthesis and catabolism.

A separate experiment examined the hypothesis that glucocorticoid-induced insulin resistance is mediated by augmented muscle E synthesis. Dexamethasone induced hyperinsulinemia in adrenalectomized rats. When the PNMT inhibitor SKF 64139 was given to adrenalectomized dexamethasone-treated rats, it reduced insulin levels and maintained normal glucose tolerance. This suggests that the insulin-lowering effects of SKF 64139 are due to improved glucose tolerance rather than direct suppression of insulin secretion. Antagonism of muscle E synthesis is a likely mechanism by which SKF 64139 improved glucose tolerance in these rats, because adrenal $\mathrm{E}$ was absent.

To more thoroughly exclude the possibility that SKF 64139 directly inhibited insulin secretion, we gave this PNMT inhibitor or placebo to normal rats. In these normal rats SKF 64139 markedly improved glucose tolerance without altering insulin levels.
Despite considerable research $(15,17,18,20,21,29,30$, 35-38) the mechanism by which glucocorticoids induce insulin resistance is uncertain. However, glucocorticoids reduce insulin-mediated glucose uptake by skeletal muscle $(15,17,18)$ and so does $E$ (14-16). Our results indicate that $E$ may mediate glucocorticoid-induced insulin resistance secondary to induction of PNMT in skeletal muscle.

In summary, dexamethasone dramatically increased muscle PNMT activity and transiently elevated muscle E levels. The PNMT inhibitor SKF 64139 lowered insulin levels in dexamethasone-treated rats and improved glucose tolerance in normal rats. Increased muscle $E$ synthesis may mediate some of the insulin resistance induced by glucocorticoids.

\section{Acknowledgments}

The authors thank Paul Shragg of the University of California, San Diego, General Clinical Research Center for help with statistics.

This work was supported by National Institutes of Health grants HL-35924 and M-01RR00827.

\section{References}

1. Axelrod, J. 1962. Purification and properties of phenylethanolamine $N$ methyltransferase. J. Biol. Chem. 237:1657-1660.

2. Saavedra, J. M., J. T. Coyle, and J. Axelrod. 1973. The distribution and properties of the non-specific $\mathrm{N}$-methyltransferase in brain. J. Neurochem. 20:743-752.

3. Pendleton, R. G., G. Gessner, and J. Sawyer. 1978. Studies on the distribution of phenylethanolamine $N$-methyltransferase and epinephrine in the rat. Res. Commun. Chem. Pathol. Pharmacol. 21:315-325.

4. Pendleton R. G., G. Weiner, and B. Jenkins. 1977. The effect of phenylethanolamine $N$-methyltransferase concentration and species difference on the inhibitory potency of SK\&F 64139. Res. Commun. Chem. Pathol. Pharmacol. 17:201213.

5. Kopp, N., J. Denoroy, B. Renaud, J. F. Pujol, A. Tabib, and M. Tommasi. 1979. Distribution of adrenaline-synthesizing enzyme activity in the human brain. J. Neurol. Sci. 41:397-409.

6. Hobel C. J., H. Parvez, S. Parvez, M. Lirette, and E. Papiernik. 1981. Enzymes for epinephrine synthesis and metabolism in the myometrium, endometrium, red blood cells, and plasma of pregnant human subjects. Am. J. Obstet. Gynecol. 141:1009-1018.

7. Ziegler, M. G., B. Kennedy, and H. E. Elayan. 1989. Extraadrenal adrenaline formation by two separate enzymes. Experientia (Based). 45: 718-720.

8. Ziegler, M. G., B. Kennedy, and H. E. Elayan. 1989. Rat renal epinephrine synthesis. J. Clin. Invest. 84:1130-1133.

9. Kennedy, B., and M. G. Ziegler. 1990. Lung epinephrine synthesis. Am. J. Physiol. 258:L227-L231.

10. Kennedy, B., and M. G. Ziegler. 1991. Cardiac epinephrine synthesis: regulation by a glucocorticoid. Circulation. 84:891-899.

11. Perry, B. D., J. M. Stolk, G. Vantini, R. B. Guchait, and D. C. U'Prichard. 1983. Strain differences in rat brain epinephrine synthesis: regulation of $\alpha$-adrenergic receptor number by epinephrine. Science (Wash. DC). 221:1297-1299.

12. Routledge, C., and C. A. Marsden. 1987. Adrenaline in the CNS: in vivo evidence for a functional pathway innervating the hypothalamus. Neuropharmacology. 26(7B):823-830.

13. Wurtman, R. J., and J. Axelrod. 1966. Control of enzymatic synthesis of adrenaline in the adrenal medulla by adrenal cortical steroids. J. Biol. Chem. 241:2301-2305.

14. Wan, D. C., and B. G. Livett. 1989. Induction of phenylethanolamine $N$-methyltransferase mRNA expression by glucocorticoids in cultured bovine adrenal chromaffin cells. Eur. J. Pharmacol. 172:107-115.

15. Struthers, A. D., D. L. Davies, D. Harland, J. S. Price, R. A. Brown, C. Quigley, and M. J. Brown. 1987. Adrenaline causes potassium influx in skeletal muscle and potassium efflux in cardiac muscle in rats: the role of $\mathrm{Na} / \mathrm{K}$ ATPase. Life Sci. 40:101-108.

16. Williams, J. H., and W. S. Barnes. 1989. The positive inotropic effect of epinephrine on skeletal muscle: a brief review. Muscle \& Nerve 12:968-975.

17. James, D. E., K. M. Burleigh, and E. W. Kraegen. 1986. In vivo glucose metabolism in individual tissues of the rat: interaction between epinephrine and insulin. J. Biol. Chem. 261:6366-6374.

18. Marfaing, P., A. Ktorza, M. F. Berthault, J. Predine, L. Picon, and L. 
Penicaud. 1991. Effects of counter regulatory hormones on insulin-induced glucose utilization by individual tissues in rats. Diabete \& Metabolisme. 17:55-60.

19. Laakso, M., S. V. Edelman, G. Brechtel, and A. D. Baron. 1992. Effects of epinephrine on insulin mediated glucose uptake in whole body and leg muscle in man. The role of leg blood flow. Am. J. Physiol. 263:E199-E204.

20. Oshima, K., N. S. Shargill, T. M. Chan, and G. A. Bray. 1989. Effects of dexamethasone on glucose transport by skeletal muscles of obese $(\mathrm{ob} / \mathrm{ob})$ mice. Int. J. Obes. 13:155-163.

21. Haber, R. S., and S. P. Weinstein. 1992. Role of glucose transporters in glucocorticoid-induced insulin resistance. GLUT4 isoform in rat skeletal muscle is not decreased by dexamethasone. Diabetes 41:728-735.

22. Stojanovska, L., G. Rosella, and J. Proietto. 1990. Evolution of dexamethasone-induced insulin resistance in rats. Am. J. Physiol. 258:E748-E756.

23. Pagano, G., P. Cavallo-Perin, M. Cassader, A. Bruno, A. Ozzello, P. Masciola, A. M. Dall'omo, and M. Imbimbo. 1983. An in vivo and in vitro study of the mechanism of prednisone-induced insulin resistance in healthy subjects. $J$. Clin. Invest. 72:1814-1820.

24. Rizza, R. A., L. J. Mandarino, and J. E. Gerich. 1982. Cortisol-induced insulin resistance in man: impaired suppression of glucose production and stimulation of glucose utilization due to a postreceptor defect of insulin action. J. Clin. Endocrinol. \& Metab. 54:131-138.

25. Kennedy, B., and M. G. Ziegler. 1990. A more sensitive and specific radioenzymatic assay for catecholamines. Life Sci. 47:2143-2154.

26. Ziegler, M. G., B. Kennedy, and H. E. Elayan. 1988. A sensitive radioenzymatic assay for epinephrine forming enzymes. Life Sci. 43:2117-2122.

27. Wong, D. L., S. J. Masover, and R. D. Ciaranello. 1981. Regulation of dopamine beta-hydroxylase synthesis and degradation. J. Biol. Chem. 256:695700.

28. Caro, J. F., and J. M. Amatruda. 1982. Glucocorticoid-induced insulin resistance. The importance of postbinding events in the regulation of insulin binding, action, and degradation in freshly isolated and primary cultures of rat hepatocytes. J. Clin. Invest. 69:866-875.

29. Karasik, A., and C. R. Kahn. 1988. Dexamethasone induced changes in phosphorylation of the insulin and epidermal growth factor receptors and their substrates in intact rat hepatocytes. Endocrinology. 123:2214-2222.

30. Orland, M. J., and M. A. Permutt. 1991. Comparative modulations of insulin secretion, pancreatic insulin content, and proinsulin mRNA in rats. Effects of $50 \%$ pancreatectomy and dexamethasone administration. Diabetes 40:181-189.

31. Stojanovska, L., G. Rosella, and J. Proietto. 1991. Dexamethasone-ınduced increase in the rate of appearance in plasma of gut-derived glucose following an oral glucose load in rats. Metab. Clin. Exp. 40:297-301.

32. Bonner-Weir, S., D. F. Trent, and G. C. Weir. 1983. Partial pancreatectomy in the rat and subsequent defect in glucose-induced insulin release. J. Clin. Invest. 71:1544-1553.

33. Kusuya, H., P. Blix, D. L. Horowitz, D. F. Speiner, and A. H. Rubenstein 1977. Determination of free and total insulin and C-peptide in insulin treated diabetics. Diabetes. 26:22-29.

34. Kennedy, B., H. Elayan, and M. G. Ziegler. 1991. Epinephrine synthesis by rat arteries. Am. J. Hypertens. 9:45-50.

35. Kahn, C. R., D. Goldfine, D. M. Neville, and P. De Meyts. 1975. Alterations in insulin binding induced by changes in vivo in the levels of glucocorticoids and growth hormone. Endocrinology. 103:1054-1066.

36. Nelson, D. H., and D. K. Murray. 1987. Dexamethasone inhibition of hydrogen peroxide-stimulated glucose transport. Endocrinology. 120:156-159.

37. Olefsky, J. M., J. Johnson, F. Liu, P. Jen, and G. M. Reaven. 1975. The effects of acute and chronic dexamethasone administration on insulin binding to isolated rat hepatocytes and adipocytes. Metab. Clin. Exp. 24:517-527.

38. Block, N. E., and M. G. Buse. 1989. Effects of hypercortisolemia and diabetes on skeletal muscle insulin receptor function in vitro and in vivo. $\mathrm{Am}$. J. Physiol. 256:E39-E48. 